\title{
Being Fair about the Design of FAIR Data Standards
}

\author{
LOUISE BEZUIDENHOUT, Institute for Science, Innovation and Society University of Oxford, Oxford, UK
}

\begin{abstract}
Since 2014 the FAIR data movement has been rapidly altering the landscape of data sharing and re-use. Support for the FAIR movement has seen the evolution of disciplinary-specific standards to foster data that are "finable, accessible, interoperable and reusable." While these exciting developments should not be minimised, it is important to interrogate how these standards are set. Key questions to ask include how representation in standard setting communities is addressed; what infrastructures and resources these emergent standards are reliant on; and how standards dictate specific interpretations of "value" and "valuable data." Asking such questions introduces a needed reflexivity into FAIR discussions, as standard setters interrogate what data practices commit present-and future-researchers to.
\end{abstract}

CCS Concepts: • Human-centered computing $\rightarrow$ Accessibility; • Social and professional topics $\rightarrow$ Professional topics;

Additional Key Words and Phrases: FAIR, data sharing, low/middle-income countries, standards

ACM Reference format:

Louise Bezuidenhout. 2020. Being Fair about the Design of FAIR Data Standards. Digit. Gov.: Res. Pract. 1, 3, Article 18 (September 2020), 7 pages.

https://doi.org/10.1145/3399632

\section{THE EVOLUTION OF THE FAIR MOVEMENT}

Since its establishment in 2014 [Wilkinson et al. 2016], the FAIR movement advocates for data to be "effectively findable, accessible, interoperable and reusable by humans and computers and, therefore, support discovery and innovation" [FAIRsFAIR 2019]. The value of the FAIR movement lies in the commitment to enhancing transparency and reproducibility in research [Boeckhout, Zielhuis, and Bredenoord 2018]. Increasingly, FAIR is framed in research policy circles as the pre-eminent means by which to realise and improve open and data-driven science more generally [European Commission 2016].

The FAIR principles do not explicitly define behaviours or standards, but rather act as a guideline for communities wishing to facilitate convergence in data collection and management practices [Pergl Sustkova et al. 2020]. Indeed FAIR-ness, like openness, is best conceptualized as a scale of application, rather than as a binary concept [Higman, Bangert, and Jones 2019]. Disciplinary communities, together with universities, policy makers, standard development organizations, service providers, and funders in many countries are working together to transform these principles into practical standards for data gathering, management, and curation practices.

A 2018 report by the European Expert Committee on FAIR data identified the complexities of turning FAIR data standards from a concept to a reality. They proposed that in research contexts the concepts of FAIR/FAIR data

Author's address: L. Bezuidenhout, Institute for Science, Innovation and Society, University of Oxford, 64 Banbury Road, Oxford, OX2 6PN, UK; email: louise.bezuidenhout@insis.ox.ac.uk.

Permission to make digital or hard copies of all or part of this work for personal or classroom use is granted without fee provided that copies are not made or distributed for profit or commercial advantage and that copies bear this notice and the full citation on the first page. Copyrights for components of this work owned by others than the author(s) must be honored. Abstracting with credit is permitted. To copy otherwise, or republish, to post on servers or to redistribute to lists, requires prior specific permission and/or a fee. Request permissions from permissions@acm.org.

(c) 2020 Copyright held by the owner/author(s). Publication rights licensed to ACM.

2639-0175/2020/09-ART18 \$15.00

https://oi.org/10.1145/3399632

Digital Government: Research and Practice, Vol. 1, No. 3, Article 18. Publication date: September 2020. 
stood as shorthand for the organization of a plethora of key resources that relate to research data. These included: "algorithms, tools, workflows, and analytical pipelines that lead to creation of the data and give it meaning. It also encompasses the technical specifications, standards, metadata, vocabularies, ontologies and identifiers that are needed to provide meaning, both to the data itself and any associated materials. Furthermore, it includes the legal and ethical specifications regarding the generation, processing, storage and sharing of research data, metadata and associated workflows and resources" [Collins et al. 2018, p. 22].

\section{DECIDING WHAT CONSTITUTES “EQUAL REPRESENTATION” IN STANDARD SETTING COMMUNITIES}

As research data standards within different disciplines begin to coalesce around specific FAIR-influenced practices and requirements, it is apparent that those organising data sharing initiatives in specific communities of practice are becoming increasingly influential [Boeckhout, Zielhuis, and Bredenoord 2018]. Nonetheless, membership to these standard-setting communities is by no means uniform. Indeed, the rapid evolution of FAIR-related groups and networks has been-at least in part-facilitated by long-standing, global, and crossdisciplinary events, such as those organized by the Research Data Alliance (RDA) and CODATA. Such events offer the opportunity for interested researchers to come together to gain information about a wide range of inter/disciplinary initiatives and have been very important in fostering community consensus and buy-in.

While membership to these organizations is open and free, attendance to these plenaries requires funding, visas, and institutional support for travel. This understandably means that researchers from low/middle-income countries (LMICs) remain less likely to be able to attend. ${ }^{1}$ Moreover, individuals representing other knowledgeproducing communities (such as citizen scientists and innovators) are often under-represented at these meetings. While these concerns are well recognized within the RDA (and other) community, ameliorating these issues is no easy task. Although participation to the formal sessions can be done remotely, much of the work on harmonization, coordination, and innovation occurs outside of these sessions. This means that researchers unable to attend physically can struggle to engage with disciplinary standard-setting discussions. Thus, individual engagement in standard setting discussions is often facilitated by proximity and personal connections.

Similarly, the FAIR movement has been championed by a small number of high-income country (HIC) institutions. While institutional expertise is to be expected (and, indeed, encouraged), their dominance in the standard setting communities can lead to certain perspectives and preferences being foregrounded. These two issues-the low representation of LMIC individuals and the dominance of certain institutions in FAIR discussions-must give pause for thought when we consider how heterogeneous current discussions actually are.

Of course, getting a truly global representation in these standard setting groups is extremely complicatedeven in an ideal setting. Whether such representation should be on nationality, regional distribution of researchers, or prestige remain unclear. Such discussions are further complicated by the tradition of voluntary service in these standard setting groups. Such challenges highlight how the balance of coordination with representation is also a necessary evil. To be most effective, a coordination effort benefits from leaders who hold a "position of authority in a given area, and be sufficiently resourced to be impactful" [Dunning, Sansone, and Teperek 2019].

It is important to recognize that not all researchers would identify the current make-up of standard setting groups as problematic. Indeed, many researchers would argue that it is solely expertise, competence, and availability that should be positively selected for in these groups. Holding such positivist approaches to data mean that they assume that data-and thus the standards that govern them-are indistinguishable from the context in which it is created. Such a position would deny that any data standards would differ according to the composition

\footnotetext{
${ }^{1}$ For instance, membership to the RDA for researchers from LMICs currently stands at around 5.7\%. Similarly, representation at the plenaries (aside from the 2018 one hosted in Gabarone, Botswana) is very limited. For instance, at the 2019 plenary in Helsinki, Finland, 0.53\% of delegates were from South America and 1.23\% from Africa (https://www.rd-alliance.org/about-us/communication-kit/rda-nutshell).

Digital Government: Research and Practice, Vol. 1, No. 3, Article 18. Publication date: September 2020.
} 
of the group. This means that addressing unequal representation in these groups is viewed solely as a means of promoting solidarity within the global community, and not as a critical necessity for the design and deployment of standards.

In contrast, however, social constructivist approaches to data and standards would advocate that the composition of the group is of critical importance to the standards that emerge. The heterogeneity of experiences, research contexts, and socio-legal backgrounds influence the standards that are set. Making use of a social constructivist lens through which to scrutinize FAIR data standards highlights some interesting topics for discussion. In particular, the heterogeneity of research contexts and value systems requires that we question whose/what values are informing the development of these standards. If standards set the norms for behaviour and dictate relationships between actors within the data landscape, whose values are dictating the evolution of the data landscape-and who should be part of standard-setting conversations?

\section{STANDARDS AS SITES OF ETHICAL CONFLICT}

The ethics of data sharing and re-use are interwoven into FAIR discussions. These include issues of safeguarding credit, trust, privacy, transparency, openness, neutrality, and intellectual property rights [Floridi 2013]. Recently, such discussions have expanded to give rise to the CARE Principles for Indigenous Data (https://www.gidaglobal.org/care) to ensure data guidelines address historical contexts and power differentials. Nonetheless, it is salient to note that while there is considerable discussion about where and when data can/not be shared, there is less critical discussion about how data comes to be valued as worth sharing.

How we value and evaluate the world around us is intimately connected with our morality. Valuation decisions determine how we go about protecting and promoting some things. The same decisions also sanction us to discard, overlook, or minimize that of little value. Setting standards-in data and elsewhere-are practices through which we are able to reinforce these decisions. Indeed, Lawrence Busch proposed that "grades and standards are part of the moral economy of the modern world" [Busch 2000, p. 273]. By reflecting the values of the society, standards act as a means of demarcating between what is valued and what is not. These same standards also dictate norms for behaviour and they foster uniformity (standardization). They thus become a means through which to discipline those who do not conform to these accepted definitions.

Such perspectives introduce an interesting ethical angle to considerations of who is setting these data standards. This allows us to consider not only how standards are codifying specific approaches to data production, but also committing practitioners to specific behaviours and dictating the contexts in which these data are produced. As mentioned above, the FAIR community recognises that the setting of data standards involves a range of practical, social, legal, ethical factors associated with the production, dissemination, and re-use of data [Collins et al. 2018, p. 22]. What is less critically examined, however, is how the access/provision/support of these factors varies around the world, and thus influences researchers' ability to enact standards that they have had no part in setting.

The concept of "data assemblages" is helpful in understanding this problem. This offers an alternative to the common "data as a discrete entity" perspective, instead positioning foregrounding "the technological, political, social and economic apparatuses and elements that constitutes and frames the generation, circulation and deployment of data" [Kitchin and Lauriault 2014]. If data is a networked entity, then data standards influence not all aspects of these data assemblages. Standards, then, are not about defining the "intrinsic properties" of the data, but determining the composition of these socio-technical systems in which present and future research will be required to occur. Exploring the connection between data standards and data assemblages raises some critical questions for current FAIR activities. In particular, it requires that we (continue to) question what technological, socio-political, and economic structures are required for the efficient implementation of any FAIR-influenced data standard.

For many FAIR practitioners, the most important elements of the movement are improving metadata, machineactionability, and controlled data access [Boeckhout, Zielhuis, and Bredenoord 2018]. The vision of FAIR as a

Digital Government: Research and Practice, Vol. 1, No. 3, Article 18. Publication date: September 2020. 
largely computational task that facilitates machine-to-machine communication is one that requires considerable technical and human resources to be enacted. These include access to new technologies, training and skills, computing and financial. Such resources may not be accessible to researchers in many data-producing contexts. These could include LMICs, as well as many citizen science groups and other community knowledge producers.

Similarly, an emerging set of studies highlight ways in which certain researchers are prohibited access to data that should be accessible online. Recent studies within LMIC research communities, for example, have highlighted the ways in which physical and social infrastructural challenges influence researchers' access to online data. For instance, low bandwidth, older software, and high teaching loads all curtail the online activities of researchers and shape their engagement with data and other resources [Bezuidenhout, Kelly, et al. 2017; Bezuidenhout, Leonelli, et al. 2017]. Other concerns about limited access are starting to appear in discussions around sanctions and access to US-based resources [Bezuidenhout et al. 2019; Kokabisaghi et al. 2019]. Moreover, recent reports of geoblocking [McDonald et al. 2018], including of key resources such as GitHub [Liao and Singh 2019], are raising concerns as to unseen barriers to access online.

These issues raise challenging questions: Could the same standards facilitating interoperability be exclusionary to the data produced by communities of researchers beyond the well-resourced elite? Should the inclusion of researchers into the global data-sharing landscape be dictated by access to resources? Should these researchers be required to dedicate already-scarce resources to achieving data standards they were not involved in setting?

Overlooking the integral link between data standards and data assemblages can lead to instances of epistemic injustice [Fricker 2007]. This could arise from the difficulties of meeting the technological and resource expectations inherent within the data standards. In turn, this could sustain the marginalization of these communities in the global data landscape. As FAIR-influenced data standards are motivated by positive commitments to resource sharing, it would be sad if the uncritical adoption of standards led to situations in which inclusivity and engagement in data-sharing landscapes is mediated by the availability of financial and technological resources. If FAIR-influenced data standards are increasingly determining the spatial organization of data producing contexts, it becomes important to question what they are committing practitioners to. Key questions would include:

- Do the standards require data be produced using specific types of equipment, software, or methodologies?

- Are the data dissemination and storage infrastructures accessible globally?

- Do setting standards expect an investment of resources for their roll-out in situ?

- Are the standards embedded into supportive regulatory and social landscapes?

\section{CHANGING RELATIONSHIPS BETWEEN ACTORS}

Standards not only dictate the spatial organization of data producing spaces, but are also intimately linked to practices of buy-in and modes of discipline. Within the FAIR movement, funding criteria [European Commission 2018], collaboration, and prestige/recognition are all increasingly serving as disciplinary measures to foster compliance [Dunning, Sansone, and Teperek 2019]. Creating social contexts that reinforce data standards can thus become a means of shutting down alternate perspectives, rather than supporting them. The "Juan Valdez problem" suggests that people conform to established standards because there are no better choices available to them [Busch and Juska 1997]. This begs the question: Does the rapid adoption of data standards reflect true community buy-in, or lack of spaces in which to raise alternatives and concerns?

Keeping such issues in mind will assist the FAIR community in guarding against "digital feudalism" [Mazzucato 2019] in which data practices and access are imposed by the few in power, rather than by the many. Critical to the future of global research is safeguarding against situations in which standards force LMIC researchers, citizen scientists, and other data producers into prescribed behaviours, environments, and trajectories. Indeed, the heterogenization of the data landscape has the potential to support exciting and disruptive research. This should be supported, rather than locking these non-HIC researchers into positions in which they continually need to "catch up" in relation to resource provision and research practices. Standards should operate as a means

Digital Government: Research and Practice, Vol. 1, No. 3, Article 18. Publication date: September 2020. 
of promoting interoperability and not as a means of unintentionally closing gaps through which alternative, but nonetheless robust, research can evolve.

Such considerations are not only pertinent for current attempts to foster global data sharing and research, but also have significant impact for the future. The landscape of global research is rapidly changing. Many LMICs have made research, development, and innovation (RDI) a core element in their future development plans [African Union 2014]. If these development plans are successful, it is likely that global research and the demographics of the global research community will be markedly different in the next 10 to 20 years. Similarly, the last years have seen a marked rise in the number of citizen science groups and alternative knowledge creation activities [Heckler et al. 2018].

Today's standard-setting communities are therefore determining practices and infrastructures that will influence research far beyond the present spheres of activity. Without critical reflection on the social aspects of these standards there is a possibility that present (and future) communities of researchers operating outside of the nexus of a few dominant countries in the Global North could be alienated as data producers. There is also the possibility that these communities, in the face of external standard/practice setting, will struggle to develop practices that truly reflect their complicated histories and current realities.

\section{EXPANDING DISCUSSIONS ON THE ETHICS OF FAIR}

As discussed by Higman et al. [2019], "little in the research data field has gained such traction and universal acceptance as the FAIR data principles" [Higman, Bangert, and Jones 2019]. Indeed, it is easy to get excited about the potential for FAIR data standards to revolutionize not only research, but also information systems more broadly. Enthusiasm about FAIR's potential to do good, however, must also be tempered by caution. As mentioned by Boeckhout and colleagues, "[o]n top of problems related to insufficient or incomplete adherence, unqualified application of the FAIR guiding principles could create additional issues. The FAIR guiding principles will therefore need to be supplemented with other principles and applied responsibly, taking additional normative considerations into account" [Boeckhout, Zielhuis, and Bredenoord 2018, p. 935]. This raises awareness of the larger challenge discussed here: that FAIR activities need to occur in a supportive landscape of ethical practice and applied responsibility. Nonetheless, how to integrate ethics into FAIR-influenced data standards setting in a meaningful way that extends beyond the traditional concerns of "trust, privacy, transparency, openness, neutrality, intellectual property rights and so forth" remains to be seen [Floridi 2013, p. 26].

As FAIR is such a new movement, discussions about the longitudinal impact of standard setting lack evidence. Thus, despite the identification of a range of different ethical challenges, it is likely that setting long lists of principles intended to dictate behaviour may be counter-productive. Indeed, as FAIR data practices emerge in disparate communities, determining what constitutes ethical standard setting will require experience, knowledge, and an understanding of the histories of these practices. Nevertheless, this is not to say that such discussions cannot be started now. Those who design the data standards need to consider the possible exclusion of present-and future-communities from engaging in the data revolution.

To safeguard against the design of standards and infrastructures that marginalize groups of data producers and users, it is important that FAIR-influenced data standards are scrutinized against key ethical concepts, such as justice. Stimulating discussion-both within standard-setting groups as well as disciplinary communities-about the social aspects of standard setting is fundamental for just futures. The flexibility within the FAIR movement allows the opportunity to design standards and infrastructures that support globally just and inclusive resource distribution. True convergence of data standards means integrating previously marginalized communities, and not simply facilitating those already connected to work together more efficiently. This could be done by initiating discussions that critically interrogate the increasing reliance of FAIR data standards on digital infrastructures and the possible establishment of a range of equal, but not identical, pathways that support the spirit of FAIR.

Key to unpacking these issues of justice and value is an understanding of how the standards being implemented came to be. Leonelli suggests that "data generation, processing and analysis are unavoidably value-ladened" and 
that "the scientific legitimacy of these activities depends on the extent to which such values are held up for public scrutiny" [Leonelli 2019, p. 319]. It is recognized that the best examples of data-intensive research already include "strategies and methods to explicitly account for the choices made during data collection, storage, dissemination and analysis" [Leonelli 2019, p. 319]. Nonetheless, it is becoming apparent that the bigger the data infrastructure, the more likely it is that such decisions become hidden or lost. Such is also true also for data standards, and it behoves those setting them to be explicit about the values and assumptions that contribute to their design. It is only by having this collective knowledge that future generations will have the flexibility to mould or reshape their data practices.

To protect future researchers from the possible harms of present decisions, it may also be helpful to consider the value of the precautionary principle [von Schomberg 2006]. This ethical principle has already been widely applied in responsible research discussions, particularly relating to biosecurity [Kuhlau et al. 2011]. The central elements of this principle place an ethical responsibility on decision-makers to justify their decisions in situations where future harm from these decisions is possible. Using the precautionary principle within FAIR discussions would put the onus on those setting the standards to consider how these same standards might influence future research, inclusivity, and agenda setting.

\section{MAKING FAIR MORE FAIR}

The concerns raised in this commentary are in no way intended to detract from the importance of the FAIR movement and the important role that FAIR data standards will play in the future of research. Indeed, data conforming to the FAIR principles can support the scientific innovations by facilitating the access and reuse of data. In turn, this will increase the speed and quality of research and enhance the returns on public investment in research.

Nonetheless, as we enter into this new milieu of research practice it is important to critically reflect not only on the possibilities but also the potential harms. World Science Day for Peace and Development 2019 used the theme of "Open Science, leaving no one behind." The sentiment of this theme can be extended to discussions on standard setting and infrastructure development-that we should not allow oversights and lack of critical scrutiny to lead us to embrace presents and futures that marginalize anyone from the riches of modern research. Expanding the ethical support for FAIR data standard setting has impacts far beyond research. In a world increasingly reliant on data and machine learning, the lessons learnt from the FAIR movement could be influential in setting the pattern for more just societies.

The recent COVID-19 pandemic has drawn attention to the critical importance of open, re-usable data and made FAIR/standard-setting discussions even more important. It is likely that the aftermath of the pandemic will bring to light new avenues for sharing and engagement brought on by the rapid response to the virus. It thus seems like a perfect time to start considering how FAIR data standards can assist in building an ethical and inclusive foundation for research in the post-COVID world.

\section{ACKNOWLEDGMENTS}

The author would like to thank Andy Nobes, Hugh Shanahan, Javier Lezaun, and the anonymous reviewer for their useful contributions to this commentary.

\section{REFERENCES}

African Union. 2014. Science, technology and innovation strategy for africa 2024. Retrieved from http://austrc.org/docs/stisa/.

Louise Bezuidenhout, Ola Karrar, Javier Lezaun, and Andy Nobes. 2019. Economic sanctions and Academia: Overlooked impact and longterm consequences. PLoS One 14, 10 (2019), e0222669. Retrieved from https://doi.org/10.1371/journal.pone.0222669.

Louise Bezuidenhout, Ann H. Kelly, Sabina Leonelli, and Brian Rappert. 2017. "\$100 Is Not Much to You": Open science and neglected accessibilities for scientific research in Africa. Crit. Pub. Health 27, 1 (2017), 39-49. Retrieved from https://doi.org/10.1080/09581596.2016. 1252832

Digital Government: Research and Practice, Vol. 1, No. 3, Article 18. Publication date: September 2020. 
Louise Bezuidenhout, Sabina Leonelli, Ann H. Kelly, and Brian Rappert. 2017. Beyond the digital Divide: Towards a situated approach to open data. Sci. Pub. Policy 44, 4 (2017), 464-475.

Martin Boeckhout, Gerhard A. Zielhuis, and Annelien L. Bredenoord. 2018. The fair guiding principles for data stewardship: Fair enough? Eur. F. Hum. Gen. 26, 7 (2018), 931-936. DOI : https://doi.org/10.1038/s41431-018-0160-0

Lawrence Busch. 2000. The moral economy of grades and standards. F. Rural Stud. 16 (2000), 273-283. D0I: https://doi.org/10.1016/S07430167(99)00061-3

Lawrence Busch and Arunas Juska. 1997. Beyond political economy: Actor networks and the globalization of agriculture. Rev. Int. Polit. Econ. Vol. 4. Winter.

Sandra Collins, Francoise Genova, Natalie Harrower, Simon Hodson, Sarah Jones, Leif Luuksonen, Daniel Mietchen, Rutu Petruuskuite, and Peter Wittenburg. 2018. Turning FAIR into reality: Final report and action plan from the European commission expert group on FAIR data. DOI : https://doi.org/10.2777/54599

Alastair Dunning, Susanna-Assunta Sansone, and Marta Teperek. 2019. The layered cake of FAIR Coordination: How many is too many? Scientific Data. Retrieved from http://blogs.nature.com/scientificdata/2019/10/22/the-layered-cake/.

European Commission. 2016. Open innovation, open science, open to the world: A vision for Europe. Brussels: Directorate-General for Research and Innovation. DOI : https://doi.org/10.2777/061652

FAIRsFAIR. 2019. Introduction. Retrieved from https://www.fairsfair.eu/.

Luciano Floridi. 2013. Distributed morality in an information society. Sci. Eng. Ethics 19, 3 (2013), 727-743. D0I:https://doi.org/10.1007/ s11948-012-9413-4

Miranda Fricker. 2007. Epistemic Injustice. Oxford University Press, UK. DOI : https://doi.org/10.1093/acprof:oso/9780198237907.001.0001

Susanne Heckler, Muki Haklay, Anne Bowser, Zen Makuch, Johannes Vogel, and Aletta Bonn. 2018. Citizen Science: Innovation in Open Science, Society and Policy. UCL Press, London. Retrieved from http://discovery.ucl.ac.uk/10058422/1/Citizen-Science.pdf.

Rosie Higman, Daniel Bangert, and Sarah Jones. 2019. Three camps, one destination: The intersections of research data management, fair and open. Insights UKSG 7. 32 (May 2019). DOI : https://doi.org/10.1629/uksg.468

Rob Kitchin and Tracey P. Lauriault. 2014. Towards critical data studies: Charting and unpacking data assemblages and their work. In Geoweb and Big Data, J. Eckert, A. Shears, and J. Thatcher (Eds.). University of Nebraska, Lincoln, NE. Retrieved from http://www.nuim. ie/progcity/.

Fatemeh Kokabisaghi, Andrew C. Miller, Farshid R. Bashar, Mahmood Salesi, Ali A. K. Zarchi, Abdalsamad Keramatfar, Mohammad A. Pourhoseingholi, Hosein Amini, and Amir Vahedian-Azimi. 2019. Impact of United States political sanctions on international collaborations and research in Iran. BMJ Global Health 4, 5 (2019), e001692. DOI : https://doi.org/10.1136/bmjgh-2019-001692

Frida Kuhlau, Anna T. Höglund, Kathinka Evers, and Stefan Eriksson. 2011. A precautionary principle for dual use research in the life sciences. Bioethics 25, 1 (2011), 1-8. DOI : https://doi.org/10.1111/j.1467-8519.2009.01740.x

Sabina Leonelli. 2019. Data-from Objects to Assets. Nature. NLM (Medline). DOI : https://doi.org/10.1038/d41586-019-03062-w

Rita Liao and Manish Singh. 2019. GitHub Confirms it has blocked developers in Iran, sSyria, and Crimea. TechCrunch. Retrieved from https://techcrunch.com/2019/07/29/github-ban-sanctioned-countries/?guccounter=1\&guce_referrer_us=aHR0cHM6Ly93d3cuZ29 vZ2xlLmNvbS8\&guce_referrer_cs=XBA7rZTb817SAMefnYsyyQ.

Mariana Mazzucato. 2019. Preventing Digital Feudalism. Project Syndicate. Retrieved from https://www.project-syndicate.org/commentary/ platform-economy-digital-feudalism-by-mariana-mazzucato-2019-10.

Allison McDonald, Matthew Bernhard, Luke Valenta, Benjamin VanderSloot, Will Scott, Nick Sullivan Cloudflare, J. Alex Halderman, Roya Ensafi, and Nick Sullivan. 2018. 403 Forbidden: A global view of CDN geoblocking. In Proceedings of the Internet Measurement Conference (IMC'18) DOI : https://doi.org/10.1145/3278532.3278552

Hana Pergl Sustkova, Kristina Maria Hettne, Peter Wittenburg, Annika Jacobsen, Tobias Kuhn, Robert Pergl, Jan Slifka et al. 2020. FAIR convergence matrix: Optimizing the reuse of existing fair-related resources. Data Intell. 2, 1-2 (2020), 158-170. DOI: https://doi.org/10. 1162/dint_a_00038

Publications Office of the European Union. 2018. Cost-benefit analysis for fair research data- policy recommendations. DOI : https://doi.org/ $10.2777 / 706548$

$\mathrm{R}$ von Schomberg. 2006. The Precautionary Principle and its normative challenges. In Implementing the Precautionary Principle: Perspectives and Prospects, E. Fisher, J. Jones, and R. von Schomberg (Eds.). Edward Elgar, Cheltenham, 19-42. Retrieved from http://books.google.com/books?hl=en\&lr=\&id=Bf5R3aM0AXUC\&oi=fnd\&pg=PA19\&dq=The+precautionary+principle+ and+its+normative+challenges\&ots=_F9VikpsyX\&sig=2KaG5arj_PHrWhJezaS_K58Oth4.

Mark D. Wilkinson, Michel Dumontier, IJsbrand Jan Aalbersberg, Gabrielle Appleton, Myles Axton, Arie Baak, Niklas Blomberg. 2016. The FAIR guiding principles for scientific data management and stewardship. Sci. Data 3 (Mar. 2016), 160018. DOI: https://doi.org/10.1038/ sdata.2016.18

Received March 2020; revised July 2020; accepted July 2020 